\title{
Enhanced Photoelectrochemical Response from Copper Antimony Zinc Sulfide Thin Films on Transparent Conducting Electrode
}

\author{
Prashant K. Sarswat and Michael L. Free \\ Department of Metallurgical Engineering, University of Utah, Salt Lake City, UT 84112, USA \\ Correspondence should be addressed to Prashant K. Sarswat; saraswatp@gmail.com
}

Received 31 May 2013; Revised 10 August 2013; Accepted 11 August 2013

Academic Editor: Leonardo Palmisano

Copyright (C) 2013 P. K. Sarswat and M. L. Free. This is an open access article distributed under the Creative Commons Attribution License, which permits unrestricted use, distribution, and reproduction in any medium, provided the original work is properly cited.

Copper antimony sulfide (CAS) is a relatively new class of sustainable absorber material, utilizing cost effective and abundant elements. Band gap engineered, modified CAS thin films were synthesized using electrodeposition and elevated temperature sulfurization approach. A testing analog of copper zinc antimony sulfide (CZAS) film-electrolyte interface was created in order to evaluate photoelectrochemical performance of the thin film of absorber materials. $\mathrm{Eu}^{3+} / \mathrm{Eu}^{2+}$ redox couple was selected for this purpose, based on its relative band offset with copper antimony sulfide. It was observed that zinc has a significant effect on CAS film properties. An enhanced photocurrent was observed for CAS film, modified with zinc addition. A detailed investigation has been carried out by changing stoichiometry, and corresponding surface and optical characterization results have been evaluated. A summary of favorable processing parameters of the films showing enhanced photoelectrochemical response is presented.

\section{Introduction}

Sulphosalt group compounds such as chalcostibite $\left(\mathrm{CuSbS}_{2}\right)$, famatinite $\left(\mathrm{Cu}_{3} \mathrm{SbS}_{4}\right)$, and tetrahedrite $\left(\mathrm{Cu}_{12} \mathrm{Sb}_{4} \mathrm{~S}_{13}\right)$ are part of a relatively new class of material containing antimony. This class can be utilized for thin film solar cell, photoelectrochemical hydrogen production, and thermoelectricity production as well as its application as a topological insulator [1-4]. The sulphosalts containing $\mathrm{Cu}, \mathrm{Sb}$, and $\mathrm{S}$ are commonly known as "CAS" which is generally a p-type semiconducting material [1-3]. It is worth noting that most of these elements are cost effective and abundant. This class of compounds (or minerals) was widely explored during 1960s and 1980s and it was found that their electronic properties are highly dependent on valance electrons in unit cells $[5,6]$. It was reported that some CAS sulphosalts act as large band gap semiconductors while some are metallic compounds, depending on the number of valence electrons and the stoichiometry. Interestingly, ab initio calculations suggest the presence of a "nontrivial 3D topological insulating" phase [4]. It was also anticipated that the electronic properties of such a class of materials can be tuned by changing various cations and anions. Recently, optical properties of these materials have been explored and it was observed that CAS compounds with different stoichiometry exhibit different band gaps. The band gap of $\mathrm{Cu}_{12} \mathrm{Sb}_{4} \mathrm{~S}_{13}$ is $\sim 1.72 \mathrm{eV}, \mathrm{CuSbS}_{2}$ shows a band gap of $1.38 \mathrm{eV}$, and $\mathrm{Cu}_{3} \mathrm{SbS}_{3}$ has a band gap of $1.84 \mathrm{eV}$ [1-4]. It was concluded that the band gap of this class of compounds is tunable and can be varied between 0.9 and $1.9 \mathrm{eV}[1,4]$. This range of band gap is perfectly suitable for thin film photovoltaic cells and solar hydrogen splitting [1-4]. Recently, various solution-processed and vacuum based techniques have been utilized to grow thin films of CAS such as solvothermal (nanocrystal ink printing), electrodeposition-sulfur annealing, and heat treatment of $\mathrm{Sb}_{2} \mathrm{~S}_{3}$-CuS layer [1-3, 7]. In most cases, assessments of the photovoltaic properties of these thin films were conducted using a photoelectrochemical cell. Earlier published reports suggest that photoelectrochemical response for chalcostibite thin film coated on ITO electrode was $\sim 0.09 \mathrm{~mA} / \mathrm{cm}^{2}$ at saturation, whereas film synthesized using electrodeposition annealing shows the change in offset current of $\sim 0.08 \mathrm{~mA} / \mathrm{cm}^{2}[2,7]$. It is important to note that 
this change in photocurrent is relatively low compared to other types of chalcogenide films [8]. Such inefficiency can hinder the sufficient utilization of CAS for solar cell applications. It is highly essential, therefore, to make additional efforts for the enhancement of photovoltaic properties of CAS material. One of the approaches can be the modification of film stoichiometry and experimental parameters. It was reported that zinc is one of the common substitutes for copper antimony sulfide sulphosalt $[5,6]$. For tetrahedrite (also a class of copper antimony zinc (or iron) sulfide), it was reported that up to $\sim 30 \%$ of copper substitution is possible with zinc or iron $[5,6]$. Phase relations of quaternary $\mathrm{Cu}-\mathrm{Zn}$-Sb-S or $\mathrm{Cu}-\mathrm{Fe}-\mathrm{Sb}-\mathrm{S}$ were discussed by Tatsuka and Morimoto [5]. It was reported that tetrahedrite is more stable when it contains a relatively high amount of copper. It was concluded that tetrahedrite decomposes into iron (or zinc) rich tetrahedrite, antimony, famatinite, and digenite. It was also reported that the $\mathrm{Cu}-\mathrm{Sb}-\mathrm{S}$ alloy system is less stable compared to the iron (or zinc) bearing CAS alloy system at room temperature [5]. Hence, in view of this information, we have systematically synthesized and investigated $\mathrm{Cu}-\mathrm{Zn}-\mathrm{Sb}-$ $S$ (CZAS) type of thin films, which is a modification of CAS films, on an FTO substrate.

\section{Experiments}

Electrodeposition of Cu-Zn-Sb Thin Films and Subsequent Sulfurization. Thin CZAS films were electrochemically grown on a fluorinated tin oxide (FTO) substrate using a bath containing ions of interest $\left(\mathrm{Cu}^{2+}, \mathrm{Zn}^{2+}\right.$, and $\left.\mathrm{Sb}^{3+}\right)$. Coelectrodeposition was done using a 3-electrode cell connected to Gamry Instruments Reference 600 potentiostat operated by Virtual Front Panel software. For synthesis of zinc-copper-antimony alloy thin as-deposited film, we utilized $50 \mathrm{~mL}$ of electrolyte containing copper sulfate pentahydrate, zinc sulfate, and antimony trichloride. It was reported that an excess of antimony is required in order to produce famatinite with low $\mathrm{CuS}$ $[1,5]$. In light of this information, three different experiments were conducted for synthesis of as-deposited film (sample 1: $0.016 \mathrm{M} \mathrm{CuSO}_{4} \cdot 5 \mathrm{H}_{2} \mathrm{O}, 0.043 \mathrm{M} \mathrm{SbCl}_{3}, 0.062 \mathrm{M} \mathrm{ZnSO}_{4}$; sample 2: $0.016 \mathrm{M} \mathrm{CuSO}_{4} \cdot 5 \mathrm{H}_{2} \mathrm{O}, 0.0172 \mathrm{M} \mathrm{SbCl}_{3}, 0.094 \mathrm{M}$ $\mathrm{ZnSO}_{4}$; sample 3: $0.016 \mathrm{M} \mathrm{CuSO}_{4} \cdot 5 \mathrm{H}_{2} \mathrm{O}, 0.062 \mathrm{M} \mathrm{SbCl}_{3}$, $\left.0.038 \mathrm{M} \mathrm{ZnSO}_{4}\right)$. The pHs of these baths were 1.57, 2.3, and 1.9, respectively. To mitigate preferential electroplating, potassium sodium tartrate was used as a complexing or chelating agent. It is a very common method to modify the electrode potential of different metal ions closure in the electrolyte (or plating solution) by conversion of simple ions into complex ions [9]. The electrodepositions were carried out at $\sim-1.6 \mathrm{~V}$. Time of electrodeposition was limited to $\sim 160-180 \mathrm{~s}$, in order to obtain $1-1.5 \mu \mathrm{m}$ thick as-deposited film. The precursor's films were annealed (duration $\sim 2 \mathrm{~h}$ ) in an evaporated sulfur environment to get CZAS thin film. Sulfurization was carried out in a tube furnace (temperature $\sim 450^{\circ} \mathrm{C}$ ), in an argon environment. Photoelectrochemical study was conducted using a Gamry PCI4/750 Potentiostat and a three-electrode system containing CZAS electrode, saturated calomel reference electrode (SCE), and a platinum counter electrode, which were immersed in an aqueous solution of $0.07 \mathrm{M} \mathrm{Eu}\left(\mathrm{NO}_{3}\right)_{3} \cdot 6 \mathrm{H}_{2} \mathrm{O}$. The advantages of europium nitrate have been discussed elsewhere [10]. To examine the photoelectrochemical responses of the CZAS films, the change in transient photocurrents was monitored, which were generated during alternating illumination from a high-intensity white light optical illuminator.

2.1. Film Characterization. Thin films were investigated by X-ray diffraction (XRD), scanning electron microscopy (SEM), X-ray photoelectron spectroscopy (XPS), Raman spectroscopy, and UV-Vis spectroscopy, in order to evaluate phase and structure, oxidation state, and morphological features. XRD patterns were obtained using a Philips X'Pert XRD diffractometer with $\mathrm{Cu} \mathrm{K} \alpha$ radiation over the $2 \theta$ range $20-80^{\circ}$. For high resolution, small step sizes and a receiving slit size of $1 / 8^{\circ}$ were used. SEM was performed using an FEI Quanta 600 scanning electron microscope. Raman spectra were obtained by using an R $3000 \mathrm{QE}$ portable Raman spectrometer (made by Raman Systems). A $785 \mathrm{~nm}$ laser with a power of $\sim 140 \mathrm{~mW}$ was used for excitation. Optical transmittance measurements were performed using an Ocean Optics spectrophotometer equipped with OOI Base 32 software. X-ray photoelectron spectroscopy (XPS) measurements were carried out using the monochromatic $\mathrm{AlK}_{\alpha}$ source equipped Kratos Axis Ultra DLD instrument. The spot size was $\sim 400 \mu \mathrm{m}$, dwell time was $\sim 200 \mathrm{~ms}$, and step size was kept $\sim 1 \mathrm{eV}$.

\section{Results and Discussion}

Figures $1(\mathrm{a})$ and $1(\mathrm{~b})$ show the X-ray diffractograms of CZAS thin films deposited on FTO substrate. It can be seen that apart from main characteristics peaks, $\mathrm{SnO}_{2}$ peaks are also prominent in this diffractogram for sample from experiment 1 (see Figure 1(a)). This diffraction analysis suggests the presence of famatinite CAS (strong peaks at $\sim 28.67^{\circ}$ and $33.7^{\circ}$ ) as well as peak at $\sim 56^{\circ}$ [1]. Sample 2 shows one distinct peak at $\sim 29.7^{\circ}$ and two low-intensity peaks at $\sim 34^{\circ}$ and $50^{\circ}$, respectively. These peaks closely match with diffraction pattern of tetrahedrite [3, 11]. Sample 3 shows almost amorphous behavior; hence, most of the analysis was focused on sample 1 and sample 2. Further investigation was also conducted to confirm phase and purity of these samples. We have synthesized some films with a relatively high amount of antimony; hence, the possibility of binary sulfide will be investigated in XPS analysis.

Raman spectra of thin films are shown in Figure 2. It can be seen that for sample 1, two distinct peaks at $\sim 335$ and $365 \mathrm{~cm}^{-1}$ are present. For sample 2 an intense peak was found at $\sim 362 \mathrm{~cm}^{-1}$. Sample 3 shows a low-intensity peak at $\sim 305 \mathrm{~cm}^{-1}$. For reference and comparison, we have investigated Raman spectra of copper antimony chalcogenide minerals [12]. It was found from the literature that chalcostibite shows a strong Raman peak at $\sim 337 \mathrm{~cm}^{-1}$, tetrahedrite at $\sim 351 \mathrm{~cm}^{-1}$, and famatinite at $\sim 333 \mathrm{~cm}^{-1}$ (strong peak), 283 and $369 \mathrm{~cm}^{-1}$ (low-intensity peak) [12]. Based on these values and our observation it can be said that experiment 1 results in 


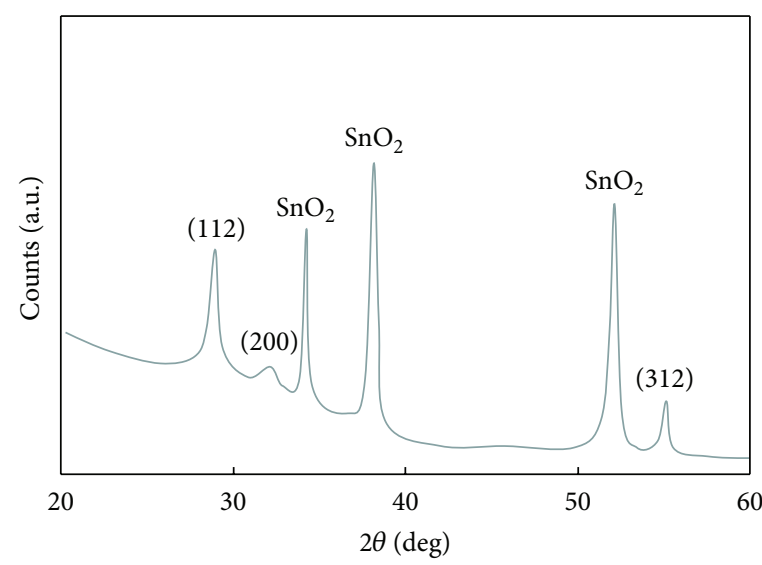

(a)

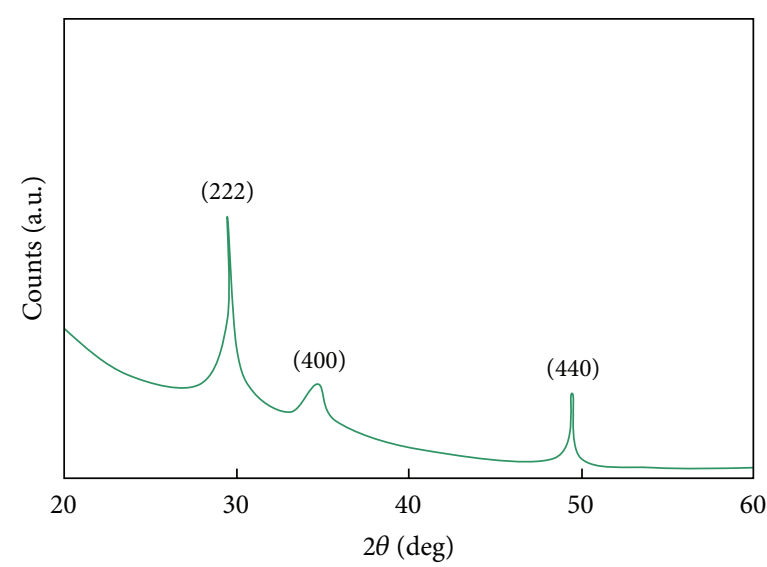

(b)

FIGURE 1: X-ray diffraction pattern of modified copper antimony sulfide thin film: (a) sample 1; and (b) sample 2.

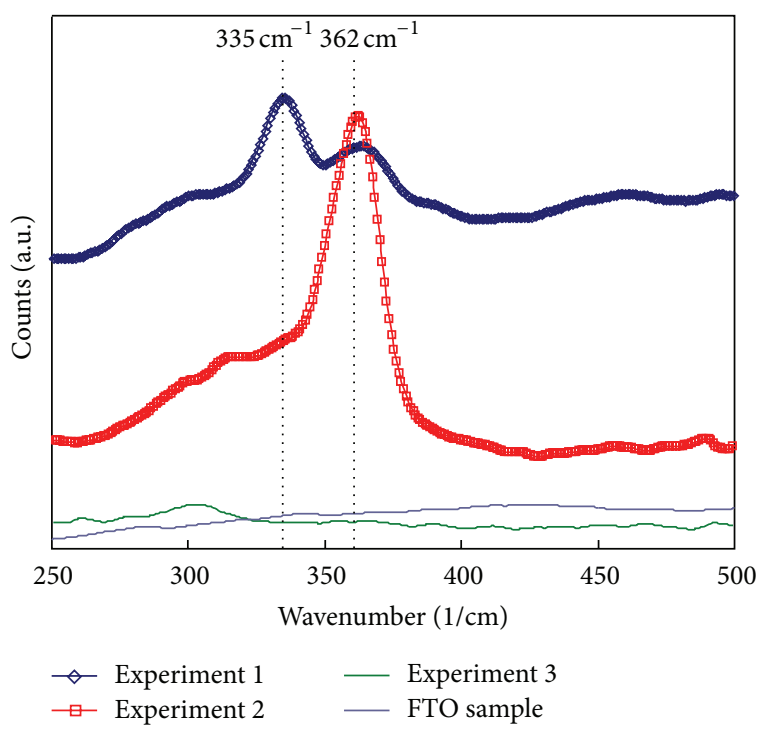

FIGURE 2: Raman spectra of copper antimony sulfide thin films of different stoichiometry and FTO coated glass sample.

the formation of famatinite phase. It was observed that our Raman peaks show a shift (from the standard peak position of undoped $\mathrm{Cu}_{3} \mathrm{SbS}_{4}$ ) towards higher frequency for CZAS film. Such an observation can be explained. Analysis of Bilbao Crystallographic Server suggests that for famatinite, $A_{1}$ mode is Raman active and strong, very similar to that for a kesterite crystal structure $[13,14]$. For a structurally similar compound, CZTS, it was reported that $A_{1}$ symmetry mode, which is a vibrational mode, shift in the frequencies of these peaks is only due to different force constants $\mathrm{f}_{\mathrm{M}-\mathrm{S}}$ and free from change in reduced mass effects [15]. The larger force constant generally results in higher Raman frequencies. Famatinite is a class I-V-VI type of semiconductor and it crystallizes in an ordered sphalerite superstructure with a $1 \overline{4} 2 m$ space group with lattice parameters $a=b=5.391 \AA$ and $c=10.764 \AA$ [1]. In randomly substituted CAS: $\mathrm{Zn}$ solid solution, zinc occupies a copper position in the lattice $[5,6]$. Hence, there is a possibility of new $\mathrm{Zn}$-S bonds in a lattice. As the mass of zinc is greater than copper, which indicates $\mathrm{f}_{\mathrm{Zn}-\mathrm{S}}>\mathrm{f}_{\mathrm{Cu}-\mathrm{S}}$, hence, it results in the shifting of a strong Raman peak. It is very likely that the strong Raman peak from sample 2 is characteristic of a tetrahedrite peak, which is possibly shifted due to stoichiometry modifications. Such modification often causes a change in bonding interaction. Both samples 1 and 2 were prepared from the electrochemical bath containing similar concentrations of copper but bath 1 contained a relatively low amount of zinc. Sample 2 contains high zinc, hence, more shift in Raman peak position is expected. Raman spectra of samples were also compared with standard samples of $\mathrm{Sb}_{2} \mathrm{~S}_{3}$ from the database. It was concluded that the presence of $\mathrm{Sb}_{2} \mathrm{~S}_{3}$ results in strong peaks at $\sim 270$ and $305 \mathrm{~cm}^{-1}$ [12], however, we did not observe strong peaks at these wavenumbers for samples 1 and 2. Such observation also eliminates the possibility of enhanced presence of $\mathrm{Sb}_{2} \mathrm{~S}_{3}$ for samples 1 and 2 . On the other hand, sample 3 shows a low-intensity peak at $\sim 306 \mathrm{~cm}^{-1}$, which indicates the presence of antimony sulfide. This investigation also suggests that there is less possibility of $\beta-\mathrm{Cu}_{3} \mathrm{SbS}_{3}$ as there is an absence of a strong peak at $321 \mathrm{~cm}^{-1}$ [16]. It is essential to note that sample 1 (famatinite rich film doped with zinc) and sample 2 (tetrahedrite rich film doped with zinc) are more photoactive. The formation of $\mathrm{Cu}_{3} \mathrm{SbS}_{3}$ (famatinite) at $400^{\circ} \mathrm{C}$ is more spontaneous compared to $\mathrm{CuSbS}_{2}, \mathrm{Cu}_{2} \mathrm{~S}$, and $\mathrm{Sb}_{2} \mathrm{~S}_{3}$ [17]. It was concluded that the formation of $\mathrm{Cu}_{3} \mathrm{SbS}_{3}$ and $\mathrm{CuSbS}_{2}$ from the parent elements is more favorable rather than from secondary sulfide phase $[5,6,17]$. The formation of famatinite from tetrahedrite is also spontaneous and remains up to temperature $\sim 770^{\circ} \mathrm{C}$. It is important to mention that no strong Raman peaks of FTO were obtained in Raman spectra of CZAS film. In contrast, very strong peaks, which correspond to FTO, were observed in XRD. An investigation of FTO coated glass sample suggests that its Raman intensity is very low compared to CZAS coated sample (see Figure 2). In this situation there are various Raman peaks of FTO between 250 and $500 \mathrm{~cm}^{-1}$, although they are not visible in CZAS spectra. 


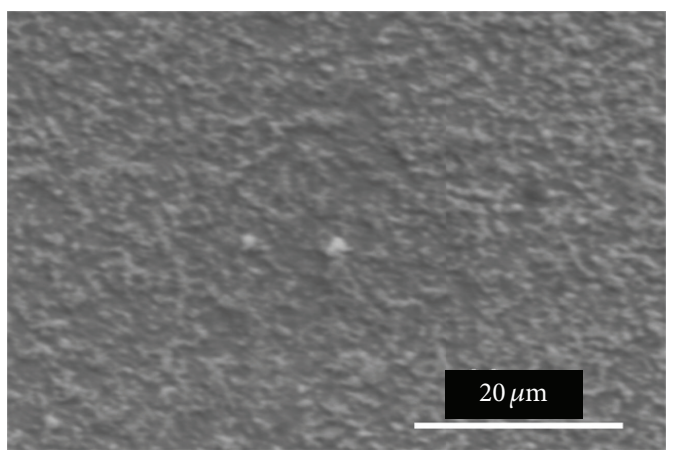

(a)

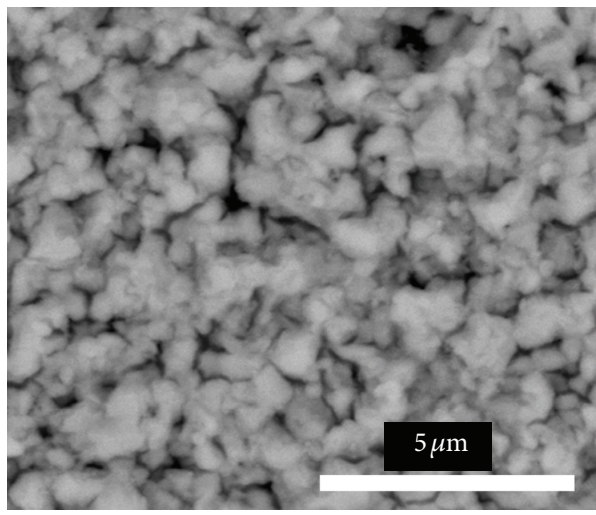

(c)

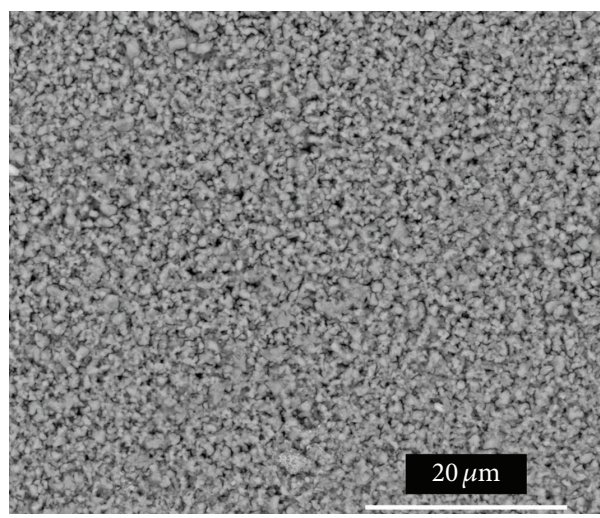

(e)

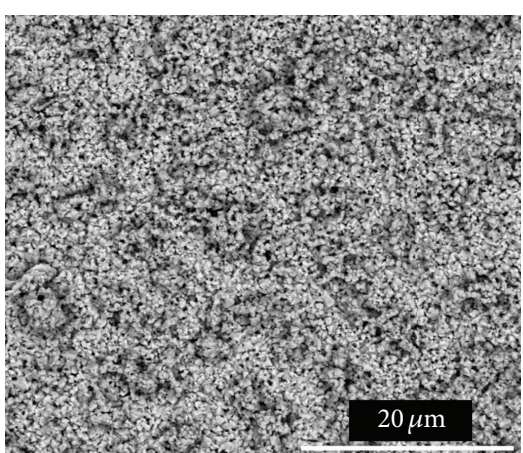

(b)

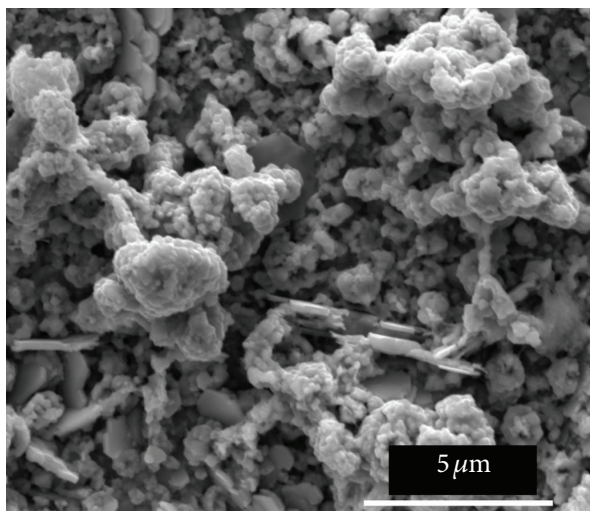

(d)

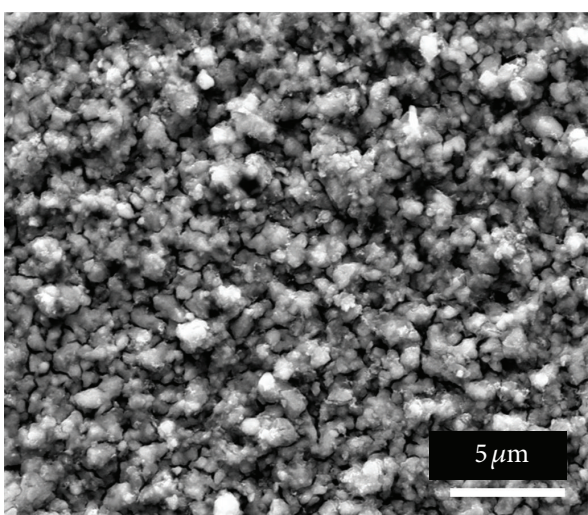

(f)

FIGURE 3: Scanning electron micrograph of modified copper antimony sulfide coated substrate: (a) low-magnification image of sample 1, (b) low-magnification image of sample 1 (different area), (c) high-magnification image of sample 1, (d) high-magnification image of sample 1 showing flower-like structures, (e) low-magnification image of sample 2, and (f) high-magnification image of sample 2.

The SEM images of CZAS samples are shown in Figures 3(a)-3(f). KCN etching was not performed in any of our samples presented and evaluated in this report. A lowmagnification SEM image (sample 1) suggests that CZAS film forms over the entire FTO substrate (see Figure 3(a)). No peel or cracking is observed. Figure 3(b) shows an image from another area, which suggests that film is rough. It also can be seen that film contains a spherical-globular type of grains in most places. Grain size of film extends from $500 \mathrm{~nm}$ to $1 \mu \mathrm{m}$. High-resolution imaging (Figure 3(c)) suggests that most of the grains are adjacent to each other and in many cases they form clusters of grains. Another high-resolution image (Figure 3(d)) suggests that thin film from sample 1 contains flake- and flower-like crystals. The average diameters for these crystals are $\sim 100 \mathrm{~nm}$. A lowmagnification image (Figure 3(e)) of sample 2 suggests that grains are more uniform compared to sample 1. Although most of the grains and film composition are uniform, at some places a few grains with different texture (Figure 3(f)) can be seen. Such texture indicates the possibility of secondary phase traces. It can be observed that most portions of the film are crack free; however, some pinholes are present. Such an 


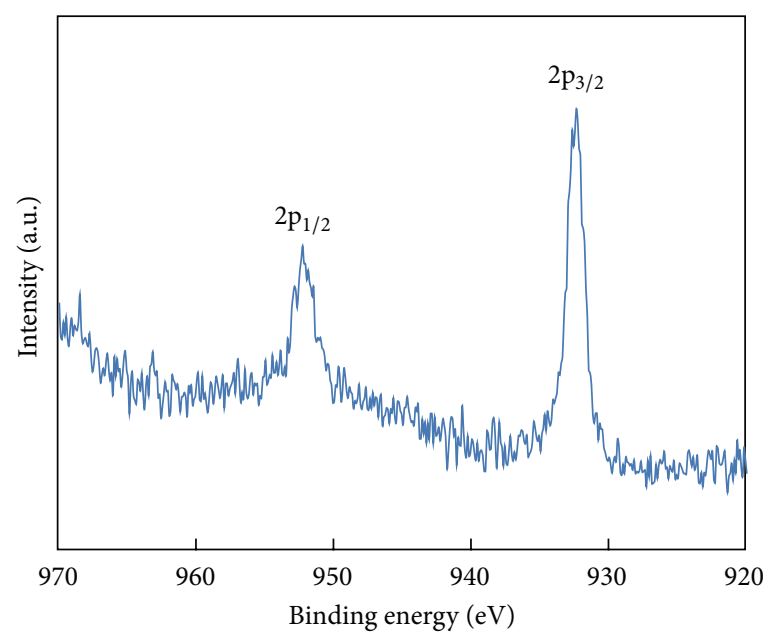

(a)

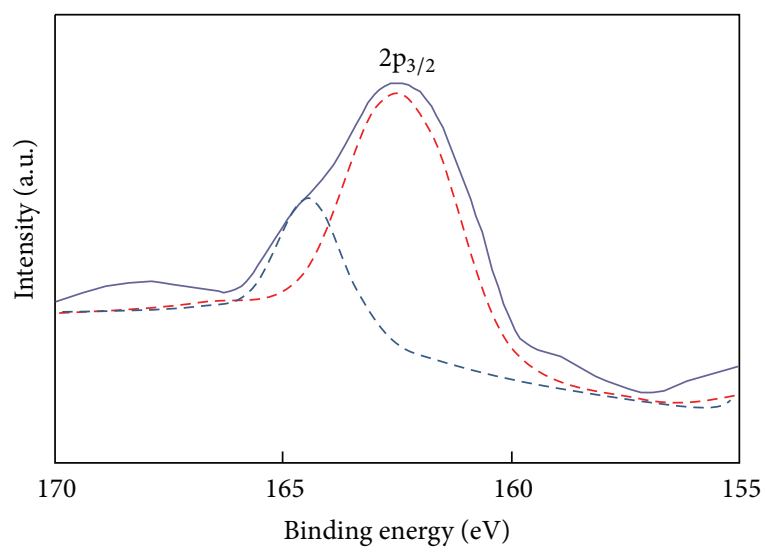

(c)

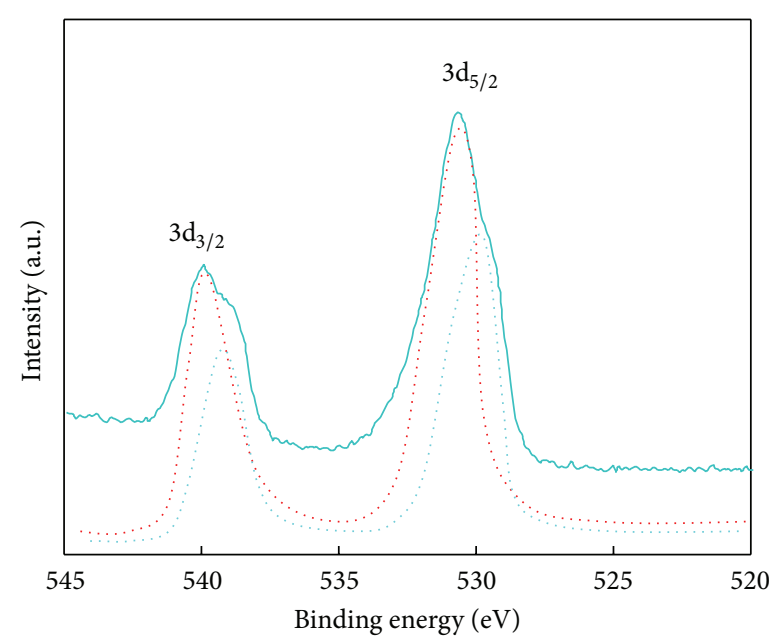

(b)

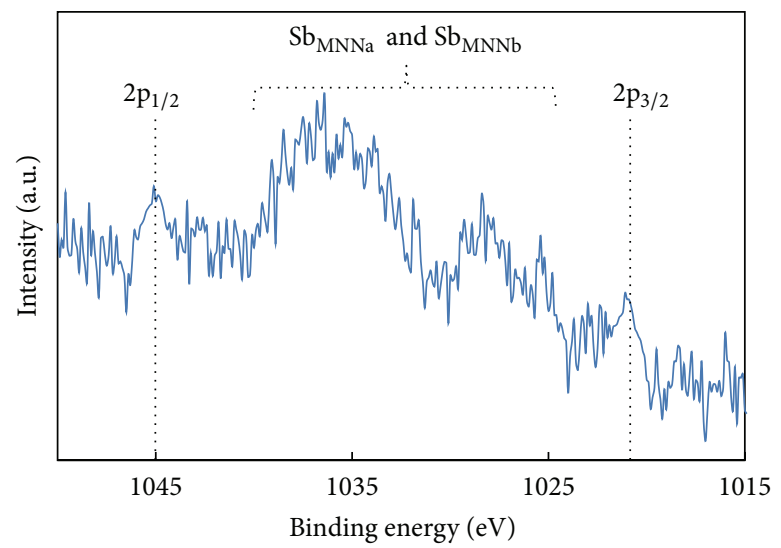

(d)

Figure 4: X-ray photoelectron spectroscopy of sample 1: (a) Cu 2p peaks, (b) Sb 3d doublet, (c) S 2p peaks, and (d) Zn 2p doublet.

observation suggests that zinc has a significant effect on film morphology, which subsequently affects device performance. Recent investigation by Warren et al. [18] indicates that high photon to current efficiency can be due to many factors, but spatial distribution of current carrying domains in the crystals plays an important role. It is very likely that highstructural complexity results in high photocurrent.

Sample showing highest photocurrent response (from experiment 1) was chosen for XPS analysis. A $2 \mathrm{p}$ doublet for copper at 932.3 and $952.1 \mathrm{eV}\left(2 \mathrm{p}_{3 / 2}\right.$ and $\left.2 \mathrm{p}_{1 / 2}\right)$ was separated by a gap of $19.8 \mathrm{eV}$ (see Figure 4(a)). These positions and gap are indications of the $\mathrm{Cu}(\mathrm{I})$ oxidation state $[19,20]$. We did not observe any satellite peaks, which correspond to the $\mathrm{Cu}(\mathrm{II})$ oxidation state. The antimony lines are found at 530.8 and $540 \mathrm{eV}$ (see Figure 4(b)) and are separated with a gap of $9.2 \mathrm{eV}$, which perfectly matches with $3 \mathrm{~d}$ doublet $\left(3 \mathrm{~d}_{5 / 2}\right.$ and $3 \mathrm{~d}_{3 / 2}$ ) [19]. Careful observation indicates that each of these peaks is overlapped with peaks at 529.6 and $539 \mathrm{eV}$. This observation suggests the presence of $\mathrm{Sb}$ (III) oxidation state. It was reported that a controlled sample of amorphous $\mathrm{Sb}_{2} \mathrm{~S}_{3}$ also shows peaks at very similar positions $\sim 529.60$ and $538.97 \mathrm{eV}$ [21]. A shift towards higher binding energy was found which indicates that $\mathrm{Sb}$ is present in the form of $\mathrm{Sb}^{5+}$. It suggests the presence of $\mathrm{A}_{3}{ }^{\mathrm{I}} \mathrm{B}^{\mathrm{V}} \mathrm{X}_{4}$ type crystal structure. One of the doublets (Figure 4(c)) of $\mathrm{S} 2 \mathrm{p}$ perfectly matches with the reported value of $2 \mathrm{p}_{1 / 2}$ at $\sim 162.9 \mathrm{eV}$ [19]. The $S$ $2 \mathrm{p}$ line also shows asymmetry, which is due to spin orbit coupling. In XPS spectra Zn 2p doublet (see Figure 4(d)) was observed at $\sim 1022 \mathrm{eV}\left(2 \mathrm{p}_{3 / 2}\right)$ and $1045 \mathrm{eV}\left(2 \mathrm{p}_{1 / 2}\right)$, which was consistent with the standard splitting $\sim 22.9 \mathrm{eV}$. It suggests $\mathrm{Zn}$ (II) oxidation state [19]. Elemental analysis suggests that the atomic ratio of $\mathrm{Cu}: \mathrm{Zn}: \mathrm{Sb}: \mathrm{S}$ is $1.18: 0.40: 1.90: 7.2$.

The optical properties of CZAS thin films (samples 1 and 2) were analyzed using Ultra Violet-Visible optical transmission spectroscopy. The transmittance of a CZAS film was examined as a function of wavelength. Using the transmittance data from the absorption spectra, the energy gap of thin film can be determined as follows:

$$
\alpha=A\left(h v-E_{g}\right)^{1 / 2}
$$

where $\alpha$ is the absorption coefficient, $A$ is a constant, $h v$ is the incident photon energy, and $E_{g}$ is the energy gap. Figure 5 shows squared absorption coefficient and incident 


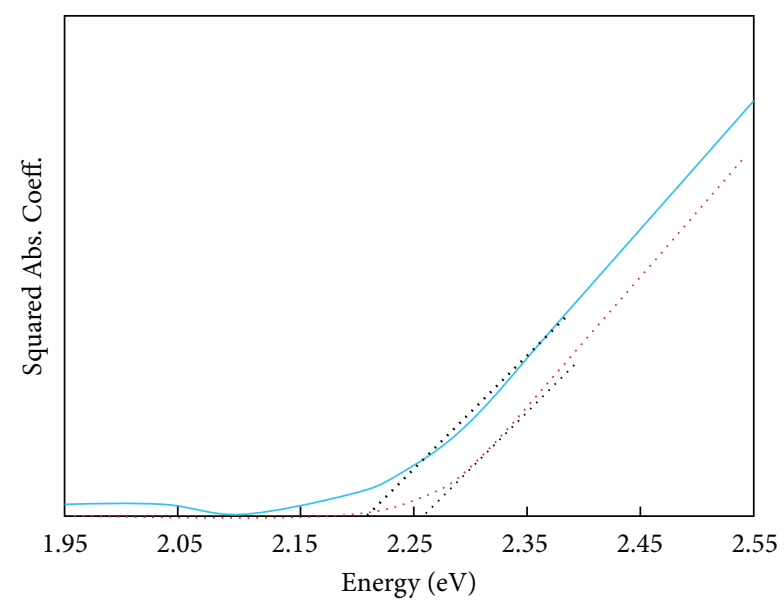

Sample 1

Sample 2

FIGURE 5: $\left(\alpha^{2}\right)$ versus photon energy $h v$ for CZAS films.

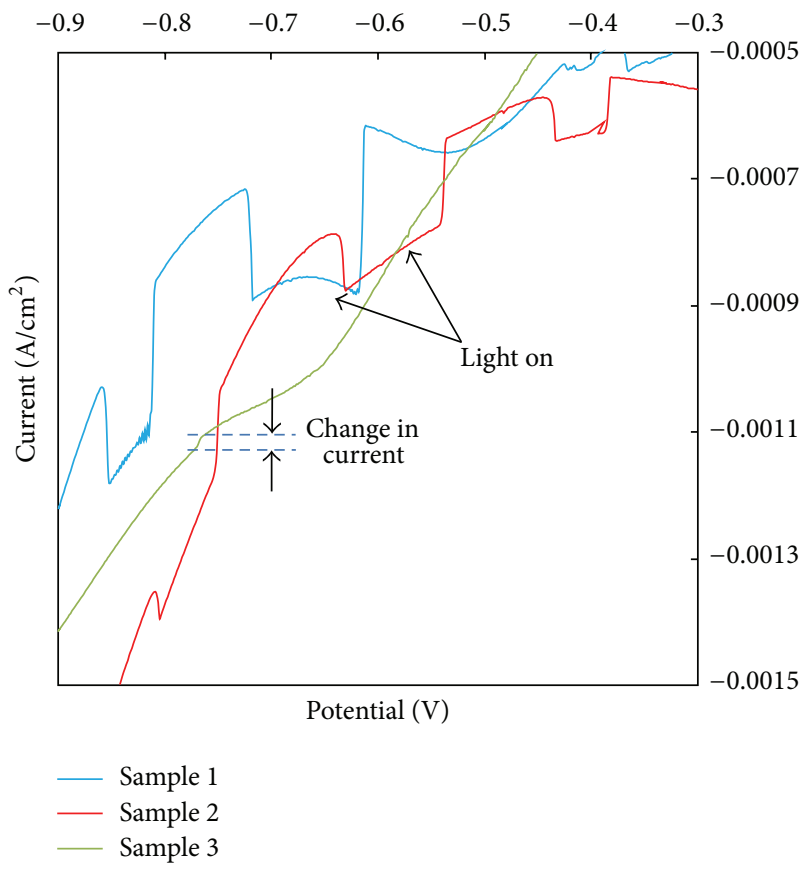

Figure 6: Photoelectrochemical response of CZAS thin films (grown on FTO substrate), immersed in europium nitrate electrolyte solution.

photon energy relationship for CZAS films, deposited on FTO coated glass. By extrapolating the squared absorption coefficient versus photon energy curve to zero, the band gap was evaluated to be $\sim 2.20 \mathrm{eV}$ (sample 1) and $\sim 2.25 \mathrm{eV}$ (sample 2).

The current density potential plots obtained after photoelectrochemical examination for three different samples are shown in Figure 6. $J-V$ curves were recorded during white LED illumination (incident illuminance on substrate $\sim 3.2 \times 10^{4}$ lux at wavelength of $\sim 550 \mathrm{~nm}$ ) and in the dark.
The photocurrent was recorded during chopping illumination and change in photocurrent was evaluated for relative photovoltaic performance. The highest photoelectrochemical response of the film (experiment 1 ) is $\sim 0.15 \mathrm{~mA}$. The dark current was very insignificant up to the biased potential of $\sim-0.6 \mathrm{~V}$ (SCE) but started increasing beyond a potential $-0.7 \mathrm{~V}$. It should be noted that this photocurrent response is relatively high ( 1.7 times greater), compared to earlier reported values $[2,7]$. Sample 2, which was prepared from the bath of depleted antimony and high zinc, showed a relatively low current response. Highest current response for this sample was $\sim 0.08 \mathrm{~mA}$, which is approximately half of the first sample. The lowest current response (overall) was obtained for sample 3, which contains the highest level of antimony. Dark current for this sample was also higher. The high photocurrent response from sample 1 can be explained based on the presence of a more stable crystalline phase, structural complexity, relatively low-band gap of film, and more uniform and interconnected grains. On the other hand, sample 2 shows some secondary phase traces on SEM, which can create a trap or recombination centers throughout the film volume. Such a phenomenon may diminish the photovoltaic performance. Another possibility of reduced photoelectrochemical performance of sample 2 is a relatively high band gap, compared to sample 1 . More analysis such as simulations using density functional theory tools and finite-difference time-domain methods are required to explain such behavior in detail. This work is in progress.

\section{Conclusions}

In summary, modified copper antimony sulfide thin films were synthesized using electrochemical growth of " $\mathrm{Cu}-\mathrm{Sb}$ $\mathrm{Zn}$ " alloy and subsequent elevated temperature sulfurization. These films were investigated for phase and structural analyses as well as for photoelectrochemical performance. Raman and XRD characterizations suggest that film grown on sample 1 is a famatinite rich, while sample 2 contains a tetrahedrite rich film. High-zinc content results in the strengthening of the force constant which subsequently causes shifting of the Raman peak towards higher frequency. The band gap of the film deposited on sample 1 (moderate antimony) was $2.20 \mathrm{eV}$, whereas band gap of the sample 2 (zinc rich film) was $\sim 2.25 \mathrm{eV}$. Thin film synthesized from an electrochemical bath containing a moderate level of antimony chloride, shows the highest photocurrent response. However, film from bath with excess antimony exhibits very poor photoelectrochemical response. Enhanced photoelectrochemical response of the modified CAS film was explained on the basis of a more stable crystalline phase, a low-band gap of film, and more uniforminterconnected grains.

\section{References}

[1] J. V. Embden and Y. Tachibana, "Synthesis and characterisation of famatinite copper antimony sulfide nanocrystals," Journal of Materials Chemistryno, vol. 22, no. 23, pp. 11466-11469, 2012. 
[2] C. Yan, Z. Su, E. Gu et al., "Solution-based synthesis of chalcostibite $\left(\mathrm{CuSbS}_{2}\right)$ nanobricks for solar energy conversion," RSC Advances, vol. 2, no. 28, pp. 10481-10484, 2012.

[3] C. An, Y. Jin, K. Tang, and Y. Qian, "Selective synthesis and characterization of famatinite nanofibers and tetrahedrite nanoflakes," Journal of Materials Chemistry, vol. 13, no. 2, pp. 301-303, 2003.

[4] Y. J. Wang, H. Lin, T. Das, M. Z. Hasan, and A. Bansil, “Topological insulators in the quaternary chalcogenide compounds and ternary famatinite compounds," New Journal of Physics, vol. 13, no. 8, Article ID 085017, 2010.

[5] K. Tatsuka and N. Morimoto, "Tetrahedrites stability relations in the Cu-Fe-Sb-S system," American Mineralogist, vol. 62, pp. 1101-1109, 1977.

[6] R. O. Sack and R. R. Loucks, "Thermodynamic properties of tetrahedrite-tennanites: constraints on the interdependence of the $\mathrm{Ag} \rightleftharpoons \mathrm{Cu}, \mathrm{Fe} \rightleftharpoons \mathrm{Zn}, \mathrm{Cu} \rightleftharpoons \mathrm{Fe}$, and $\mathrm{As} \rightleftharpoons \mathrm{Sb}$ exchange reactions," American Mineralogist, vol. 70, no. 11-12, pp. 12701289, 1985.

[7] D. Colombara, L. M. Peter, K. D. Rogers, J. D. Painter, and S. Roncallo, "Formation of $\mathrm{CuSbS}_{2}$ and $\mathrm{CuSbSe}_{2}$ thin films via chalcogenisation of Sb-Cu metal precursors," Thin Solid Films, vol. 519, no. 21, pp. 7438-7443, 2011.

[8] S. C. Riha, S. J. Fredrick, J. B. Sambur, Y. Liu, A. L. Prieto, and B. A. Parkinson, "Photoelectrochemical characterization of nanocrystalline thin-film $\mathrm{Cu}_{2} \mathrm{ZnSnS}_{4}$ photocathodes," ACS Applied Materials and Interfaces, vol. 3, no. 1, pp. 58-66, 2011.

[9] L. J. Durney, Graham's Electroplating Handbook, Springer, New York, NY, USA, 1984.

[10] P. K. Sarswat and M. L. Free, "An evaluation of depletion layer photoactivity in $\mathrm{Cu}_{2} \mathrm{ZnSnS}_{4}$ thin film," Thin Solid Films, vol. 520, no. 13, pp. 4422-4426, 2012.

[11] X. Lu and D. T. Morelli, "Natural mineral tetrahedrite as a direct source of thermoelectric materials," Physical Chemistry Chemical Physics, vol. 15, no. 16, pp. 5762-5766, 2013.

[12] http://rruff.info (data base).

[13] M. I. Aroyo, A. Kirov, C. Capillas, J. M. Perez-Mato, and H. Wondratschek, "Bilbao crystallographic server. II. Representations of crystallographic point groups and space groups," Acta Crystallographica A, vol. 62, no. 2, pp. 115-128, 2006.

[14] P. K. Sarswat, M. L. Free, and A. Tiwari, "Temperaturedependent study of the Raman A mode of $\mathrm{Cu}_{2} \mathrm{ZnSnS}_{4}$ thin films," Physica Status Solidi B, vol. 248, no. 9, pp. 2170-2174, 2011.

[15] C. Huang, Y. Chan, F. Liu et al., "Synthesis and characterization of multicomponent $\mathrm{Cu}_{2}\left(\mathrm{Fe}_{x} \mathrm{Zn}_{1-x}\right) \mathrm{SnS}_{4}$ nanocrystals with tunable band gap and structure," Journal of Material Chemistry A, vol. 1, no. 17, pp. 5402-5407, 2013.

[16] A. Pfitzner, " $(\mathrm{CuI})_{2} \mathrm{Cu}_{3} \mathrm{SbS}_{3}$ : copper iodide as solid solvent for thiometalate ions," Chemistry, vol. 3, no. 12, pp. 2032-2038, 1997.

[17] J. R. Craig and W. R. Lees, "Thermochemical data for sulfosalt ore minerals: formation from simple sulfides," Economic Geology, vol. 67, no. 3, pp. 373-377, 1972.

[18] S. C. Warren, K. Voïtchovsky, H. Dotan et al., "Identifying champion nanostructures for solar water-splitting," Nature Materials, vol. 12, pp. 842-849, 2013.

[19] "NIST X-ray Photoelectron Spectroscopy Database, Version 4.1," National Institute of Standards and Technology, Gaithersburg, http://srdata.nist.gov/xps/, 2012.

[20] P. K. Sarswat and M. L. Free, "Utility of by-product quantum dots obtained during synthesis of $\mathrm{Cu}_{2} \mathrm{ZnSnS}_{4}$ colloidal ink," Ceramics International, 2013.
[21] H. Yang, M. Li, L. Fu, A. Tang, and S. Mann, "Controlled assembly of $\mathrm{Sb}_{2} \mathrm{~S}_{3}$ nanoparticles on silica/polymer nanotubes: insights into the nature of hybrid interfaces," Scientific Reports, vol. 3, no. 1336, 2013. 

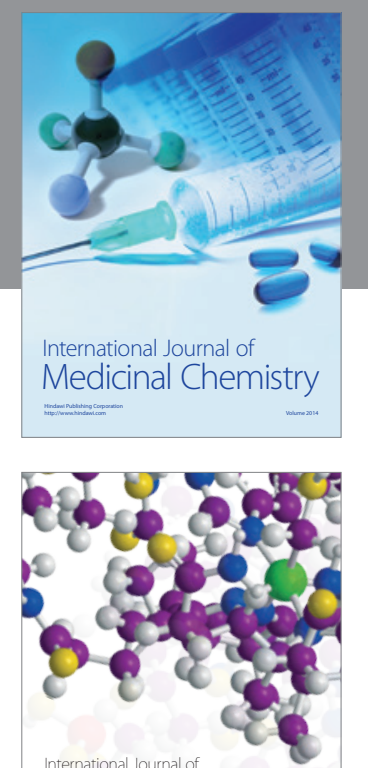

\section{Carbohydrate} Chemistry

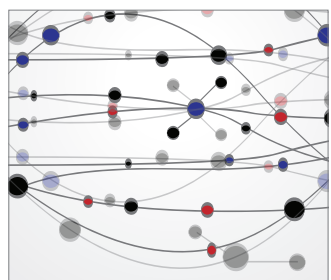

The Scientific World Journal
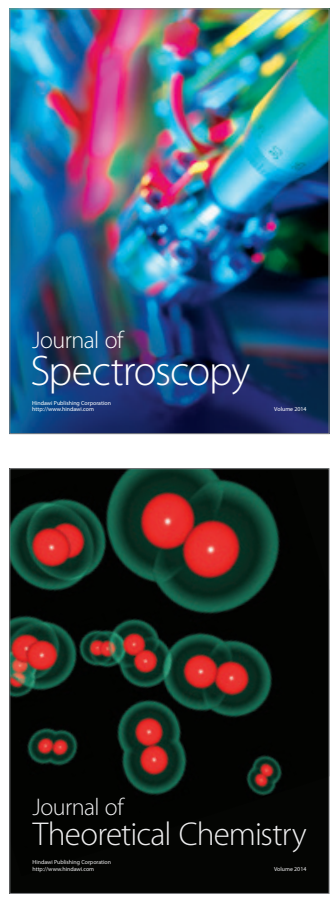
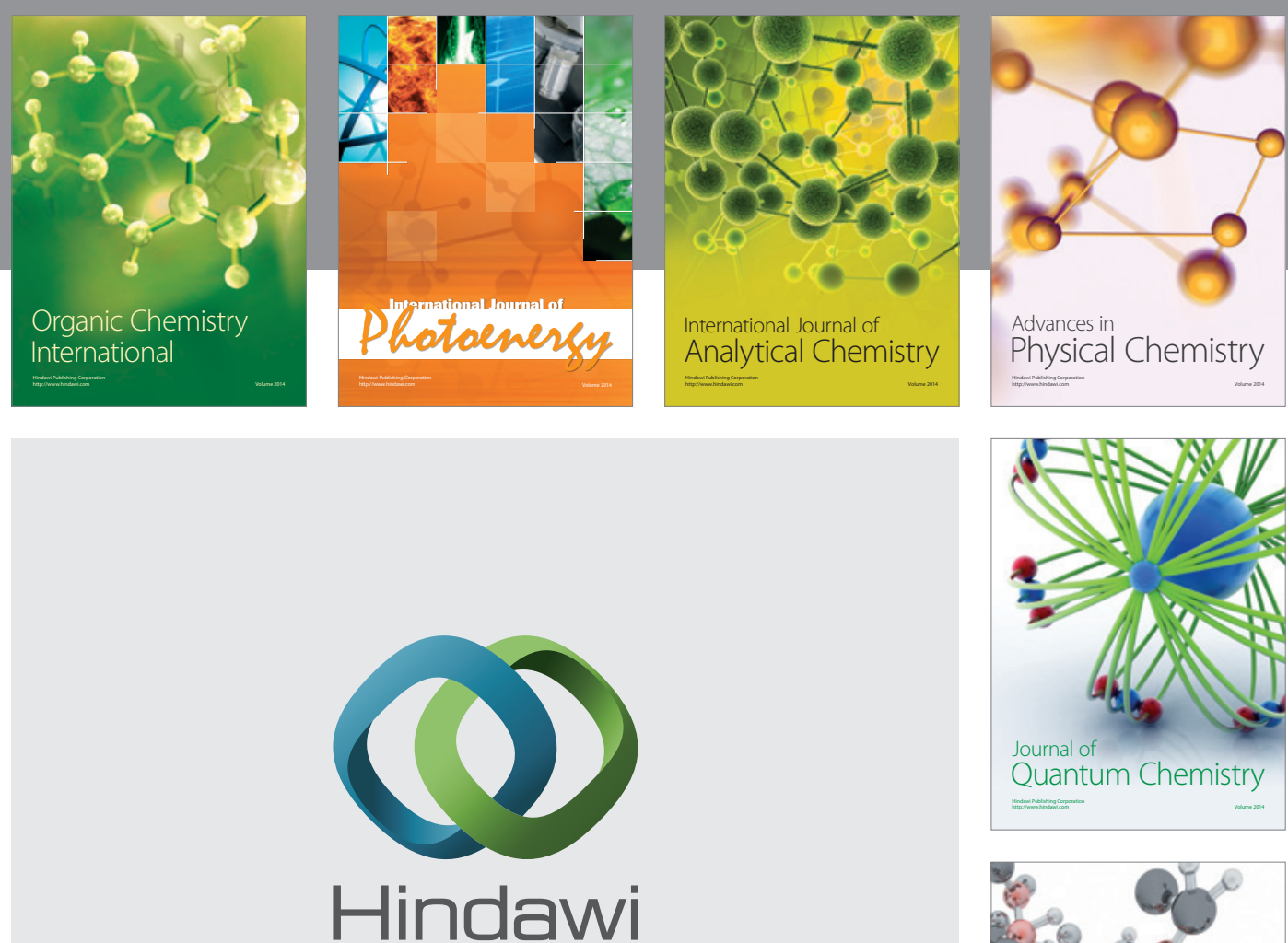

Submit your manuscripts at

http://www.hindawi.com

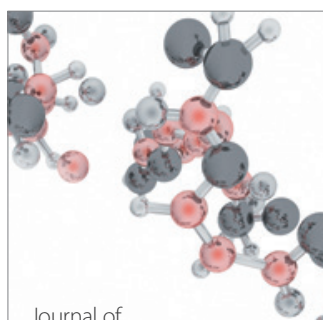

Analytical Methods

in Chemistry

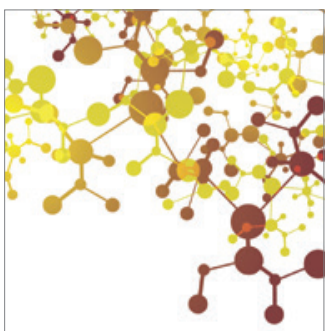

Journal of

Applied Chemistry

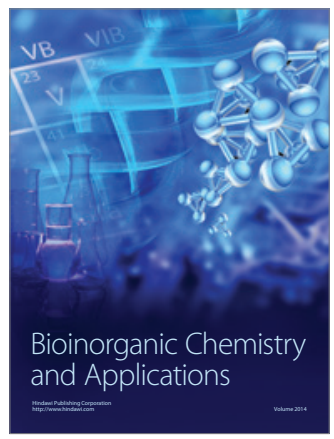

Inorganic Chemistry
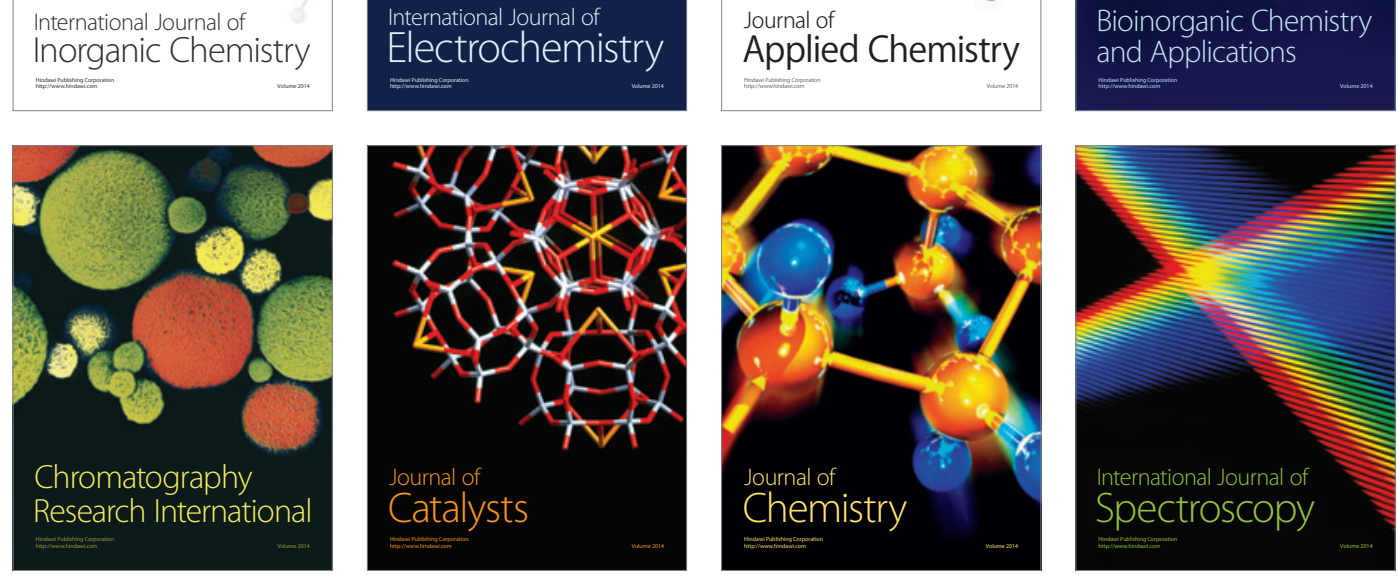